\title{
Knowledge Index for Measuring Knowledge and Adopting Scientific Methods in Treatment of Reproductive Problems of Dairy Animals
}

\author{
M. S. Meena ${ }^{1}$, K. M. Singh ${ }^{1}$, B. S. Malik ${ }^{2}$, B. S. Meena ${ }^{2} \&$ Manish Kanwat $^{3}$ \\ ${ }^{1}$ Division of Socio-economic and Extension, ICAR Research Complex for Eastern Region, ICAR Parisar, PO: \\ Bihar Veterinary College, Patna, Bihar, India \\ ${ }^{2}$ Dairy Extension Division, National Dairy Research Institute, Karnal, Haryana, India \\ ${ }^{3}$ ICAR Research Centre for NEH Region, AP Centre Basar, Arunachal Pradesh, India \\ Correspondence: M. S. Meena, Division of Socio-economic and Extension, ICAR Research Complex for \\ Eastern Region, ICAR Parisar, PO: Bihar Veterinary College, Patna, Bihar, India. Tel: 91-947-046-5688 E-mail: \\ s.mohar.meena@gmail.com
}

Received: May 24, 2012 Accepted: June 13, 2012 Online Published: August 24, 2012

doi:10.5539/jas.v4n10p81 URL: http://dx.doi.org/10.5539/jas.v4n10p81

\begin{abstract}
Reproductive problems among dairy animals are one of the major causes of loss in dairy sector. These problems can be tackled by imparting appropriate knowledge to the livestock owners. An attempt was made to measure the knowledge of livestock owners by developing a knowledge test on reproductive problems of dairy animals. The study was undertaken in Karnal district of Haryana state, India. Data were solicited from 300 livestock farmers who had at least one milch animal at the time of investigation. In addition to developing schedules for socio-economic variables, a knowledge test was also developed for measuring knowledge construct. Data were solicited on scientific treatment of affected dairy animals and 59.54\% knowledge was observed on reproductive traits. Study indicates that majority of livestock farmers adopted scientific methods for treating their animals. Respondents' age, extension contact and milk production were positively and significantly correlated with knowledge. Therefore, imparting quality practical training and periodical assessment of performance of lay inseminators for improving their skills and knowledge regarding estrus detection and insemination needs to be emphasized. Extension machinery has to be an ideal bridge between research/development institutions and dairy farmers for their catalytic effect (Meena \& Malik, 2009). Extensive awareness programs are needed for inculcating scientific outlook among livestock farmers on these complex problems. Easy accessibility of veterinary hospital at village level can reduce the adoption of indigenous technical knowledge in treatment of these complex problems.
\end{abstract}

Keywords: reproductive problems, livestock owners, knowledge, scientific treatment

\section{Introduction}

Dairy animals' reproductive diseases result in economic losses caused by decreased production as well as increased treatment and preventive measurement costs. Reproduction can be negatively affected in many ways (Bellows \& Short, 1994). Retained placentas and cesarean delivery can result in a prolonged postpartum interval to conception, causing increased days open and decreased milk production (Barkema et al., 1992; Van Werven, 1992). Infertility regardless of cause is a major reason for culling the animals. Culling due to repeat breeding adds significant cost to milk production (Beever, 2006). Hence, maintaining infertile animal is an economic burden on dairy owners. By and large, 10-30\% of lactation in cattle is affected by infertility and reproductive disorders. Repeat breeding (Meena et al., 2008; Meena \& Malik, 2009), anestrus (Meena \& Malik, 2009) and infertility (Meena et al., 2008) are some of the prominent reproductive problems under Indian conditions. However, extreme climate also affect the reproductive efficiency (Nanda et al., 2003). About, $13.6 \%$ to $18.2 \%$ wrong inseminations were perceived under Indian conditions (Kaul \& Prakash, 1993). Jeyakumari et al. (2003) estimated economic impact of postpartum reproductive disorders as $21.01 \%$ and $34.25 \%$ in university and private farms, respectively. Loss was more in prolapse, followed by retained placenta and metritis. Productive and reproductive performance of dairy animals is largely affected by inadequate dietary management and health coverage against existing and emerging diseases. Imbalanced concentration of minerals is one of the possible causes of reproductive problems (Ahmet et al., 2008). The major constraints identified in eradicating reproductive problems were lack of facility of veterinary doctors during night, high incidence of repeat breeding, and lack of good quality bulls at village level 
(Meena \& Malik, 2009). Since, reducing infertility is vital for better reproductive performance, hence proper knowledge of reproductive problems acts as a change vehicle for desired change in enhancing dairy animal's fertility. Hence, an attempt was made to measure the knowledge of livestock owners on reproductive problems; and scientific amelioration of these problems.

\section{Research Methods}

\subsection{Locale of Study and Sampling Plan}

The study was conducted in Karnal district of Haryana state, India. Haryana is situated in northern region of India flanked by Punjab, Rajasthan, Delhi and Uttar Pradesh. Karnal district lies between $29^{\circ} 09^{\prime} 50^{\prime \prime}$ and $29^{\circ} 59^{\prime}$ north latitude and $76^{\circ} 31^{\prime} 15^{\prime \prime}$ and $77^{\circ} 12^{\prime} 45^{\prime \prime}$ east longitude at 235 and 252 meters mean sea level. Climate ranges from dry and hot summers to cold winters. Average annual rainfall is about $744.7 \mathrm{~mm}$. All six blocks of Karnal district namely, Karnal, Gharaunda, Nissing, Nilokheri, Assandh and Indri were selected for this study. Using random sampling technique two villages from each of the six blocks and 25 farmers (5 farmers from each category i.e. landless, marginal, small, medium and large) from each village were selected. Thus a total of 300 farmers constituted the sample. However while selecting the farmers it was kept in mind to select only those farmers who had at least one milch animal. Schedules were developed for measuring the socio-economic (education, social participation, family size, land holding, milk production, milk consumption, milk sale and herd size), psychological (economic motivation and attitude towards dairy farming) and communicational variables (extension contact and mass media exposure). A knowledge test was developed to measure the knowledge of livestock owners on reproductive traits. Data were solicited through personal interview method.

\subsection{Development of Knowledge Test}

A knowledge test was developed using the procedure described by Linguist (1951).

a) Collection of items: The content of knowledge test is composed of questions called items. A comprehensive list of items of reproductive traits of dairy animals was prepared by consulting of relevant literature and experts of National Dairy Research Institute, Karnal. The veterinary assistant surgeons and stockmen further validated the applicability and suitability of these traits in the study area. Criteria for the items selection were (i) It should promote thinking (ii) It should have a certain difficulty, and (iii) It should differentiate well informed from less informed. Using this method, a total of 49 items on reproductive traits were selected to form the initial test index/battery to carry out item analysis for developing a knowledge test.

b) Form of questions: All 49 items formed the knowledge test and the questions were objective and dichotomous to facilitate easy and objective scoring.

c) Pre-testing and item analysis: Preliminary test consisting of 49 statements were administered to 30 non-sample respondents of study area and their responses were obtained and subjected to difficulty index, discrimination index and point-bi-serial correlation as given below:

i) Difficulty index: The difficulty of an item varies from individual to individual. When a respondent answers a question/item correctly, it was assumed that the question was less difficult for him. The assumption in this question/item statistics of difficulty was that difficulty was linearly related to level of respondents' knowledge about reproductive traits. The difficulty index for each of the 49 items was calculated by dividing the total correct responses for a particular question/item by total number of respondents as under

$$
\mathrm{D}_{\mathrm{I}}=\frac{\mathrm{N}_{\mathrm{C}}}{\mathrm{N}}
$$

Where, $\quad \mathrm{D}_{\mathrm{I}}=$ Difficulty index;

$\mathrm{N}_{\mathrm{C}}=$ Number of respondents answering correctly;

$\mathrm{n}=$ Total number of respondents.

ii) Discrimination index: If the statement is answered by some respondents correctly and not by others, such a statement has greater power to discriminate more knowledgeable from less knowledgeable ones than another statement which is either answered correctly by everyone or none in the sample. If a statement is so simple that it can be correctly answered by everyone or is too difficult to be correctly answered by anyone, it does not have power to discriminate among respondents' with varying level of knowledge. In a way, the items carrying higher discrimination power implicitly indicates that such items are moderately difficult, and they are the ones that discriminate between the ones who answer it correctly from those who are unable to do so. The discrimination power of all the 49 items were worked out by following method. 
First, respondents were arranged in descending order on basis of their performance in whole test. Out of this list, top $27 \%$ and bottom $27 \%$ of respondents were treated as high and low groups. For each question, number of top $27 \%\left(\mathrm{~N}_{\mathrm{H}}\right)$ and bottom $27 \%\left(\mathrm{~N}_{\mathrm{L}}\right)$ who answered it correctly were counted. The discrimination index was calculated as under.

$$
D_{i}=\frac{N_{H}-N_{L}}{n}
$$

Where, $\quad \mathrm{D}_{\mathrm{i}}=$ Discrimination index;

$\mathrm{N}_{\mathrm{H}}=$ Number of respondents in $27 \%$ high groups who answered correctly;

$\mathrm{N}_{\mathrm{L}}=$ Number of respondents in $27 \%$ low group who answered correctly;

$\mathrm{n}=$ Number of respondents in $27 \%$ sample.

iii) Point bi-serial correlation: The main aim of calculating point bi-serial correlation was to work out the internal consistency of items that is the relationship of total scores to a dichotomized answer to any given item. In a way, validity power of item was computed by correlation of individual item of whole test. Point bi-serial correlation for each of item to preliminary knowledge test was calculated (Garrett, 1966).

$$
r_{p} b i s=\left(M_{p}-M_{q}\right) / S D \times P . Q
$$

Where,

$$
\begin{aligned}
& r_{p} \text { bis = Point bi-serial correlation. } \\
& M_{p}=\text { Mean of the total scores of the respondents who answered the item correctly. } \\
& M_{q}=\text { Mean of total scores of respondents who answered item incorrectly. } \\
& \text { SD = Standard deviation of entire sample. } \\
& P=\text { Proportion of respondents giving correct answer to item. } \\
& Q=\text { Proportion of respondents giving incorrect answer to item. }
\end{aligned}
$$

The calculated point bi-serial correlation was tested with (N-2) degree of freedom.

iv) Final selection of items: The items having difficulty index between $0.25-0.75$, discrimination index above 0.20 and bi-serial correlation significant at 5\% level were finally selected for final knowledge test. A total of 20 items constituted the knowledge test.

v) Reliability of knowledge test: The reliability of test was assessed by using split half technique. The test consisting of 20 items was administered to 30 respondents selected randomly in non-sample areas. The responses to all the twenty items were scored as 1 for correct and 0 for incorrect. The total scores obtained by each of the respondents on odd and even numbered items in respect of two halves of test were calculated separately. The Pearson product moment correlation coefficient between the two sets of scores was calculated. The ' $r$ ' value thus calculated as 0.79 which was significant at $1 \%$ level of probability. Thereby, indicating that this test had high internal consistency.

vi) Validity of knowledge test: The validity of knowledge test was established through content validity. All possible care was taken in incorporation of the statements covering all aspects on reproductive traits. All the statements were subjected to item difficulty, discrimination index and point bi-serial correlation before selection of the final statements. Hence it was logical to assume that the test satisfies representation as well as sensible method of test construction, the criteria for contest validity.

Knowledge test consisted of 20 statements. For an individual livestock farmer, minimum and maximum knowledge scores were 20 and 60, respectively. Each trait measured independently and an overall knowledge was also calculated through the knowledge index.

\section{Results and Discussion}

$$
\text { Knowledge Index }=\frac{\text { Score obtained by respondents }}{\text { Maximum obtainable score }} \text { X } 100
$$

\subsection{Socio-economic Attributes of Farmers}

Table 1, describes the socio-economic attributes of the farmers. A perusal of this table revealed that about 47 percent belonged to young age $(<31$ years) however, nearly 44 percent were in the middle age category ranging from 31 to 49 years. Only one-tenth belonged to old age category (49 years). Most of the farmers $(50.34 \%)$ were educated up to $5^{\text {th }}$ standard however one-fourth of total were illiterate $(26 \%)$. Nearly one-tenth $(13 \%)$ were educated up to $8^{\text {th }}$ standard. Only a few farmers had secondary and higher educational qualifications. Social 
participation of livestock owners $(73.33 \%)$ was medium. Farmers were either member or participated in up to 3 social organizations. Most of the respondents, $(62.67 \%)$ had 5 to 8 members in their family and agriculture was their main occupation (73.34\%). Majority of farmers (75.00\%) produced 13-51 litres/day with nearly one-tenth farmers were producing more than 51 litres milk/day. Mostly respondents $(81.67 \%)$ were consuming $5-14$ litres milk/day. Milk selling pattern were ranged from 4 to $41 \mathrm{~kg}(72.67 \%)$ followed by more than $41 \mathrm{~kg} / \mathrm{day}(12.66 \%)$. About seventy six percent respondents had 3-9 animals in their herd. Further, 71.67 percent farmers had medium level of economic motivation. Mostly farmers (66\%) had neutral attitude towards dairy farming. However, 21.33 percent were in favor of dairy farming. Most of the farmers $(71.34 \%)$ had medium level of extension contact followed by low (20.33\%) extension contact. Extent of exposure to mass media was medium as perceived by 59.34 percent farmers followed by high and low category each $(20.33 \%)$.

Table 1. Socio-economic profile of livestock farmers, Karnal district, Haryana, India (N=300)

\begin{tabular}{|c|c|c|}
\hline Profiles of livestock farmers & Category & $\%$ \\
\hline \multicolumn{3}{|l|}{ Socio-economic profile } \\
\hline \multirow[t]{3}{*}{ Age (in years) } & Young $(<31)$ & 46.67 \\
\hline & Middle (31-49) & 43.67 \\
\hline & Old $(>49)$ & 09.66 \\
\hline \multirow[t]{5}{*}{ Education } & $0=$ Illiterate & 26.00 \\
\hline & $1=$ Primary & 50.34 \\
\hline & 2=Middle & 13.00 \\
\hline & $3=$ Secondary & 06.33 \\
\hline & $4=$ Senior secondary & 04.33 \\
\hline \multirow[t]{3}{*}{ Social participation } & No & 06.00 \\
\hline & Medium $(<3)$ & 74.33 \\
\hline & $\operatorname{High}(>3)$ & 19.67 \\
\hline \multirow[t]{3}{*}{ Family size (numbers) } & $<5$ & 21.00 \\
\hline & $5-8$ & 62.67 \\
\hline & $>8$ & 16.33 \\
\hline \multirow[t]{3}{*}{ Main occupation } & $1=$ Agriculture & 73.34 \\
\hline & 2=Dairying & 08.33 \\
\hline & $3=$ Others & 18.33 \\
\hline \multirow[t]{3}{*}{ Milk production (in litre) } & $<13$ & 13.67 \\
\hline & $13-51$ & 75.00 \\
\hline & $>51$ & 11.33 \\
\hline \multirow[t]{3}{*}{ Milk consumption (in litre) } & $<5$ & 03.66 \\
\hline & $5-14$ & 81.67 \\
\hline & $>14$ & 14.67 \\
\hline \multirow[t]{4}{*}{ Milk sale (in litre) } & No milk sale & 13.67 \\
\hline & Low $(<4)$ & 01.00 \\
\hline & Medium (4-41) & 72.67 \\
\hline & High $(>41)$ & 12.66 \\
\hline \multirow[t]{3}{*}{ Herd size (numbers) } & Low $(<3)$ & 10.00 \\
\hline & Medium (3-9) & 76.33 \\
\hline & Large $(>9)$ & 13.67 \\
\hline \multicolumn{3}{|l|}{ Psychological profile } \\
\hline \multirow[t]{3}{*}{ Economic motivation } & Less $(<7)$ & 13.66 \\
\hline & Medium (7-8) & 71.67 \\
\hline & $\operatorname{High}(>8)$ & 14.67 \\
\hline \multirow[t]{3}{*}{ Attitude towards dairy farming } & Unfavorable $(<14)$ & 12.67 \\
\hline & Neutral (14-19) & 66.00 \\
\hline & Favorable $(>19)$ & 21.33 \\
\hline \multicolumn{3}{|l|}{ Communicational profile } \\
\hline \multirow[t]{3}{*}{ Extension contact } & Low $(<8)$ & 20.33 \\
\hline & Medium (8-13) & 71.34 \\
\hline & High $(>13)$ & 08.33 \\
\hline \multirow[t]{3}{*}{ Mass media exposure } & Low $(<4)$ & 20.33 \\
\hline & Medium (4-6) & 59.34 \\
\hline & $\operatorname{High}(>6)$ & 20.33 \\
\hline
\end{tabular}




\subsection{Knowledge of Livestock Farmers}

Study reveals that 74 percent dairy farmers had medium level of knowledge regarding reproductive traits of dairy animals followed by 13 percent in low and high categories each (Figure 1). Table 2 shows the knowledge regarding individual reproductive traits. Farmers' knowledge on age of maturity of crossbred cattle was 65.33 percent. It is logically justified as most of the farmers had at least one or two crossbred cattle and getting time-to-time information regarding scientific dairy farming practices from different communication sources. In the study area, farmers had 53.79 percent knowledge regarding maturity age of indigenous cattle. The indigenous cattle population was less than the crossbred cattle, so they had somewhat slight knowledge about indigenous cattle as compared to crossbred.

Table 2. Farmers knowledge on reproductive traits of dairy animals, Karnal district, Haryana, India (N=300)

\begin{tabular}{clc}
\hline Sl. No. & Reproductive traits & Knowledge (\%) \\
\hline 1 & Maturity age of crossbred cattle & 65.33 \\
2 & Maturity age of indigenous cattle & 53.79 \\
3 & Maturity age of buffalo & 70.33 \\
4 & Dry period of dairy animals & 55.79 \\
5 & Calving interval of crossbred cattle & 57.44 \\
6 & Calving interval of buffalo & 60.22 \\
7 & Required services for conception in each heat & 58.00 \\
8 & Age of indigenous cattle at first calving & 52.22 \\
9 & Age of crossbred cattle at first calving & 65.44 \\
10 & Age of buffalo at first calving & 67.44 \\
11 & Heat symptoms of dairy animals & 67.00 \\
12 & Advanced pregnancy allowance for dairy animals & 49.78 \\
13 & Required days for repetition of heat cycle & 63.67 \\
14 & Required time of placenta removal in case of retained placenta & 46.33 \\
15 & Gestation period of cow & 75.29 \\
16 & Gestation period of buffalo & 82.89 \\
17 & Days required after calving for dairy animals to come again in the heat (service period) & 56.11 \\
18 & Better method for pregnancy diagnosis & 42.22 \\
19 & Proper time of insemination after observed heat & 55.22 \\
20 & Days required after conception for pregnancy diagnosis & 46.33 \\
& & 59.54 \\
\hline
\end{tabular}

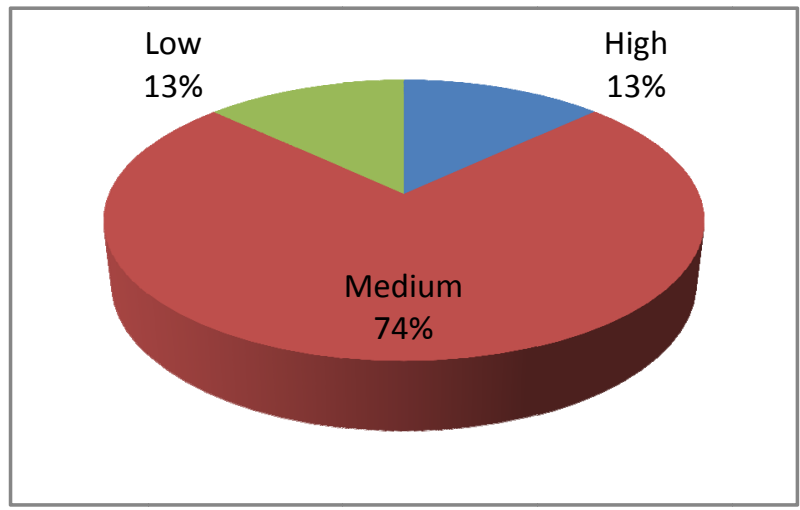

Figure 1. Farmers' knowledge on reproductive traits of dairy animals 
Locale of the study is the part of main tract of world famous Murrah buffalo. As a result, farmers of this area had more knowledge (70.33\%) about maturity age of buffalo as compared to cattle. Knowledge regarding dry period of dairy animals was found to be 55.79 percent, which is partially satisfactory from milk production point of view for next lactation. Farmers were practicing less than two months (60 days) dry period which is recommended. Farmers' knowledge on calving interval of crossbred cattle was 57.44 percent, which was not so good. It is logically justified that there was more incidence of repeat breeding in crossbred cattle, which affect the calving interval. Farmers' had somewhat more knowledge (60.22\%) in case of calving interval of buffaloes as farmers were traditional rearers of buffaloes. Knowledge about services per conception was not so good (58\%). Only a few farmers knew about recommended two artificial inseminations for conception in each heat. They had knowledge regarding age of crossbred cattle at first calving but they have 52.22 percent knowledge about the age of indigenous cattle at the time of first calving.

Farmers had more knowledge of rearing more number of buffaloes which is resulted in good knowledge about age of buffalo at first calving $(67.44 \%)$. Respondents had good knowledge $(67 \%)$ regarding heat symptoms of dairy animals, as heat symptoms are very common and can be easily detected by the farmers. It was observed that use of concentrate was fed to the animal on the basis of milk yield and not the body weight of the animal. Only few farmers were aware about the advanced pregnancy allowance to dairy animals which reflected in their knowledge $(49.78 \%)$ regarding this particular trait. A good knowledge was found in case of required days for repetitive heat cycle $(63.67 \%)$ as farmers had good knowledge on heat symptoms. In case of retained placenta, farmer's knowledge was poor $(46.33 \%$ ) regarding the removal of placenta and they were also not aware about bad effects of retained placenta.

Farmers had sound knowledge (75.29\%) about gestation period of cattle, as they were familiar with this trait. The knowledge on gestation period of buffalo was found more than cattle $(82.89 \%)$ as they were rearing more number of buffaloes compared to cattle thus buffaloes owners were more knowledgeable and experienced about this trait. The knowledge about time required after calving for dairy animals to again come in heat (service period), was 56.11 percent as it depended on overall maintenance and feeding of animals. Farmers had poor knowledge $(42.22 \%)$ concerning the scientific methods (rectal palpation) for pregnancy diagnosis as they usually followed the traditional methods for pregnancy diagnosis i.e., body improvement. Respondents had 55.22 percent knowledge on proper time of insemination, however, knowledge about days required for pregnancy diagnosis after conception was average $(46.33 \%)$. They believed that the body weight improvement was the best method for pregnancy diagnosis. Nevertheless, overall knowledge of livestock farmers on reproductive traits was 59.54 percent which was quite satisfactory. Gite (1980) reported slightly less knowledge (53.78\%) regarding scientific dairy farming practices (SDFPs) while Mahipal (1983) observed slightly higher knowledge (67.84\%). Singh and Thomas (1992) observed less knowledge (37\%). Sanvendana (2009) observed more knowledge in male counterpart $(48.48 \%)$ than female (38.54\%). Tak (2010) experienced lower knowledge among farmers which ranged from 22.73 to $29.70 \%$ regarding udder health-care practices.

\subsection{Adoption of Scientific Methods for Treatment of Reproductive Problems}

Scientific treatment of fertility problems is a key factor for increasing milk production. In case of fertility problems, respondents had to rely on various sources of information. According to knowledge, farmers opted for various measures to overcome the problems. Findings (Figure 2) indicate that majority of respondents (88.88\%) treated their animals scientifically in case of torsion of uterus and 84.50 percent in metritis/endometritis. Most of farmers $(81.25 \%)$ visited the veterinary assistant surgeons for treatment of cystic ovaries. A large number of farmers $(80.39 \%)$ also approached veterinary staff in case of dystocia and few opted for indigenous technical knowledge for treatment of fertility problems. The reason behind high percentage for treatment of fertility problems scientifically is that fertility problems are complex in nature; hence, it is difficult for farmers to observe and treat them at their own level. About 74 percent respondents took their animals to veterinary hospital for treating repeat breeding problems. In case of prolapse of vagina/uterus, 60.41 percent farmers consulted veterinary doctors for treatment of their affected animals. This fertility problem could be identified by close observation earlier or at the time of parturition when this incidence occurs. Remaining farmers adopted indigenous technical knowledge in case of anestrus and retained placenta. Absence of veterinary hospital, lack of awareness and locally available village quack forced the dairy farmers' to adopt traditional methods. 


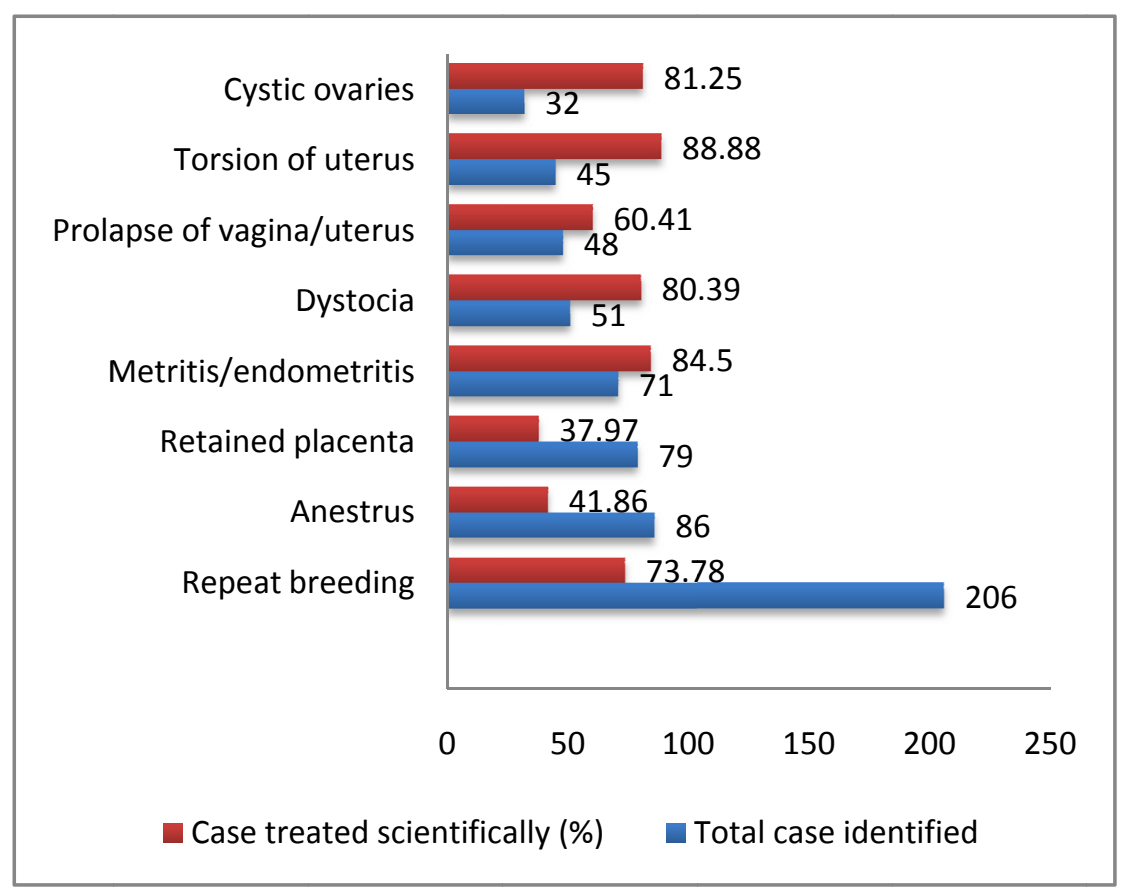

Figure 2. Identification and scientific treatment of reproductive problems

\subsection{Correlating Socio-economic Attributes and Knowledge of Livestock Farmers}

Farmers' socio-economic attributes were correlated with the knowledge (Table 3). Study reveals that age was positively and significantly $(p<0.01)$ correlated with knowledge, which implies that knowledge increases with the age and farmers traditionally have more knowledge regarding these traits. Milk production and knowledge was found significant at 5 percent level of probability, implying thereby that farmers who produced more milk were more knowledgeable. It can be inferred from these results that higher milk production stimulates interest of dairy farmers to know more and more about reproductive traits of dairy animals. Farmers' extension contact had significant correlation $(p=<0.01)$ with the knowledge. Farmers having more contact with extension personnel had increased knowledge level as it is obvious to consult reliable and credible sources of information. Thereby most of knowledge they accumulate was through these sources only.

Table 3. Correlating socio-economic attributes and knowledge of livestock farmers

\begin{tabular}{clc}
\hline Sl. No. & Socio-economic attributes & Correlation coefficient ' $r$ ' values \\
\hline 1 & Age & $0.3390^{* *}$ \\
2 & Education & 0.1477 \\
3 & Social participation & 0.1776 \\
4 & Family size & 0.0600 \\
5 & Land holding & -0.0111 \\
6 & Milk production & $0.1993^{*}$ \\
7 & Milk consumption & -0.1062 \\
8 & Milk sale & 0.0838 \\
9 & Herd size & 0.0832 \\
10 & Economic motivation & 0.0533 \\
11 & Attitude toward dairy farming & 0.1860 \\
12 & Extension contact & $0.2064^{*}$ \\
13 & Mass media exposure & 0.1463 \\
14 & Information source & 0.1343 \\
15 & Credibility of information source & $0.3200^{* *}$ \\
$* p<0.05 * * p<0.01$ & \\
\hline
\end{tabular}




\section{Conclusions and Recommendations}

Reproductive problems are complex in nature and cause heavy losses to livestock farmers. Study reveals that overall knowledge of livestock owners on reproductive traits was quite satisfactory. Most of the farmers adopted scientific methods for treating their reproductive problems. However, use of indigenous technical knowledge too was prevalent in the area. Respondents' age, extension contact and milk production had positive and significant correlation with knowledge level. It can therefore be said that there is a need to impart the quality practical training and periodical assessment of performance of local inseminators for improving their skill and knowledge regarding estrus detection and insemination. Extension machinery can be an ideal bridge between research institutions and dairy farmers for the catalytic effect. Through the organization of awareness program, scientific attitude can be inculcated among livestock farmers on these complex problems. However, easy accessibility of veterinary hospital at village level can check the role of quacks and indigenous technical knowledge in treatment of these complex problems.

\section{References}

Ahmet, C., Ilker, S., Hasan, A., \& Seyrek, K. (2008). Concentrations of some elements in dairy cows with reproductive disorders. Bulletin of Veterinary Institute Pulawy, 52, 109-12.

Barkema, H. W., Schukken, Y. H., Guard, C. L., Brand, A., \& Weyden, G. C. (1992). Cesarean section in dairy cattle: A study of risk factors. Theriogenology, 37, 489. http://dx.doi.org/10.1016/0093-691X(92)90206-7

Beever, D. E. (2006). The impact of controlled nutrition during the dry period on dairy cow health, fertility, and performance, Animal Reproduction Science, 96, 212-26. http://dx.doi.org/10.1016/j.anireprosci.2006.08.002

Bellows, R. A., \& Short, R. E. (1994). Reproductive losses in the beef industry. In factors affecting calf crop. M. J. Fields and R. S. Sands (Ed.). p. 109. Boca Raton, FL. CRC Press.

Garrette, H. E. (1966). Statistics in psychology and education, International Book Bureau, Hyderabad.

Gite, N. R. (1980). A study on training needs of crossbred cattle owners under Lab to Land programme. M.Sc. Thesis, Kurukshetra University, Kurukshetra, India.

Jeyakumari, M., Thirunavukkarasu, M., \& Kathiravan, G. (2003). Economic impact of postpartum reproductive disorders on dairy farms, Indian Journal of Animal Sciences, 73(12), 1360-62.

Kaul, V., \& Prakash, B. S. (1993). Application of milk progesterone estimation for detecting incidence of false estrus detection and ovulation failure in zebu and cross bred cattle and Murrah buffaloes. Indian Journal of Animal Sciences, 64(12), 1054-57.

Kumari, S. (2009). Information management on reproductive disorders in bovines through farmer livestock school. Ph.D. Thesis, National Dairy Research Institute (Deemed University), Karnal, Haryana, India.

Linquist, E. F. (1951). Educational measurements, Part-II. American Council of Education, Washington, USA.

Mahipal. (1983). A study on of socio-economic and psychological correlates in adoption of dairy innovations in the ORP area of NDRI, Karnal. Ph.D. Thesis, Kurukshetra University, Kurukshetra, India.

Meena, H. R., Ram, H., Sahoo, A., \& Rasool, T. J. (2008). Livestock husbandry scenario at high altitude Kumaon Himalaya, Indian Journal of Animal Sciences, 78(8), 882-86.

Meena, M. S., \& Malik, B. S. (2009). Participatory identification of reproductive problems among dairy animals and constraints faced by farmers in Haryana. Indian Journal of Animal Sciences, 79(11), 1172-1175.

Nanda, A. S., Barar, P. S., \& Prabhakar, S. (2003). Enhancing reproductive performance in dairy buffalo, major constraints and achievement, Reproduction (suppl.), 61, 27-36.

Singh, L., \& Thomas, C. K. (1992). Knowledge and adoption in the technology of dairy farming and its constraints. Indian Dairyman, 44(9), 445-450.

Tak, A. M. (2010). Udder Health-Care Practices Followed by Dairy Farmers: An Exploratory Study in NDRI Adopted Villages. M. Sc. Thesis, NDRI Deemed University, Karnal (Haryana), India. 